\title{
Differential localization of A-Raf regulates MST2- mediated apoptosis during epithelial differentiation
}

\author{
J Rauch $^{*, 1}$, D Vandamme ${ }^{1}$, B Mack ${ }^{2}$, B McCann ${ }^{1}$, N Volinsky ${ }^{1}$, A Blanco ${ }^{3}$, O Gires ${ }^{2}$ and W Kolch ${ }^{\star, 1,3,4}$
}

A-Raf belongs to the family of oncogenic Raf kinases that are involved in mitogenic signaling by activating the MEK-ERK pathway. Low kinase activity of A-Raf toward MEK suggested that A-Raf might have alternative functions. We recently identified A-Raf as a potent inhibitor of the proapoptotic mammalian sterile 20-like kinase (MST2) tumor suppressor pathway in several cancer entities including head and neck, colon, and breast. Independent of kinase activity, A-Raf binds to MST2 thereby efficiently inhibiting apoptosis. Here, we show that the interaction of A-Raf with the MST2 pathway is regulated by subcellular compartmentalization. Although in proliferating normal cells and tumor cells A-Raf localizes to the mitochondria, differentiated non-carcinogenic cells of head and neck epithelia, which express A-Raf at the plasma membrane. The constitutive or induced re-localization of A-Raf to the plasma membrane compromises its ability to efficiently sequester and inactivate MST2, thus rendering cells susceptible to apoptosis. Physiologically, A-Raf re-localizes to the plasma membrane upon epithelial differentiation in vivo. This re-distribution is regulated by the scaffold protein kinase suppressor of Ras 2 (KSR2). Downregulation of KSR2 during mammary epithelial cell differentiation or siRNA-mediated knockdown re-localizes A-Raf to the plasma membrane causing the release of MST2. By using the MCF7 cell differentiation system, we could demonstrate that overexpression of A-Raf in MCF7 cells, which induces differentiation. Our findings offer a new paradigm to understand how differential localization of Raf complexes affects diverse signaling functions in normal cells and carcinomas.

Cell Death and Differentiation (2016) 23, 1283-1295; doi:10.1038/cdd.2016.2; published online 19 February 2016

A-Raf is a member of the Raf family of serine-threonine protein kinases, which comprises A-Raf, B-Raf, and Raf-1. Raf kinases are at the apex of the three-tiered Raf/MEK/ extracellular signal-regulated kinase (ERK) (mitogen-activated protein kinase (MAPK)) pathway regulating fundamental cellular functions, including differentiation, transformation, apoptosis, proliferation, and metabolism. ${ }^{1,2}$ Activation of Ras GTPases at the cell membrane initiates Raf kinase activation and sequential phosphorylation and activation of the serinethreonine kinases MEK1/2 and ERK1/2.3,4 In comparison to Raf-1 and B-Raf, A-Raf is only weakly activated by oncogenic $\mathrm{H}$-Ras and $\mathrm{Src}^{5}$ and is a poor MEK kinase,$^{5-8}$ which is due to unique non-conserved amino acid substitutions in the $\mathrm{N}$-region. ${ }^{9}$ Only recently, the first somatic oncogenic mutations of A-Raf were identified in lung adenocarcinomas ${ }^{10}$ and Langerhans cell histiocytosis. ${ }^{11,12}$ We recently showed that A-Raf and Raf-1, independent of their kinase activity, bind the proapoptotic mammalian sterile 20-like kinase (MST2) thereby suppressing MST2 activation and MST2-induced apoptosis. ${ }^{1-17}$ MST2 employs several mechanisms to induce apoptosis including the transcriptional induction of PUMA, ${ }^{14} \mathrm{a}$ $\mathrm{BH} 3$ domain protein that causes mitochondrial depolarization and subsequent cell death. ${ }^{18}$ Although Raf- 1 counteracts
MST-2-mediated apoptotic signaling by suppressing the activation of MST2 only in quiescent cells or upon apoptotic stimulation, ${ }^{14,15}$ A-Raf binds constitutively to MST2. ${ }^{16}$ This anti-apoptotic role may explain why A-Raf levels are elevated in a variety of malignancies. ${ }^{16,19-21}$ Both A-Raf and MST2 were shown to localize to the mitochondria in tumor cell lines as well as primary tumors. ${ }^{16} \mathrm{~A}$-Raf was reported to associate with the mitochondrial transport system proteins hTOM and $\mathrm{hTIM},{ }^{22}$ but the physiological significance of this interaction is still unknown.

A-Raf mRNA expression levels were shown to be upregulated during adipocyte differentiation. ${ }^{23}$ DA-Raf1 and DA-Raf2, two alternative splice forms of A-Raf, which contain the amino-terminal Ras-binding domain, but lack the kinase domain, act as dominant-negative antagonists of activated Ras and positive regulators of myogenic differentiation. ${ }^{24}$

MAPK signaling is regulated and organized by a group of molecular scaffolds, coordinating the efficient interaction of MAPK components, forming functional subcomplexes and signaling nodes thereby regulating signal intensity and specificity. ${ }^{2,25}$ In addition, scaffolds are crucial for the spatial regulation of signaling events by targeting their clients to different localizations thereby increasing the variety of signals

\footnotetext{
${ }^{1}$ Systems Biology Ireland, University College Dublin, Dublin, Ireland; ${ }^{2}$ Clinical Cooperation Group Molecular Oncology, Department of Head and Neck Research, LudwigMaximilians-Universität München, Helmholtz Zentrum München, German Research Center for Environmental Health, Munich, Germany; ${ }^{3}$ Conway Institute of Biomolecular \& Biomedical Research, University College Dublin, Dublin, Ireland and ${ }^{4}$ School of Medicine and Medical Science, University College Dublin, Belfield, Dublin 4, Ireland. *Corresponding author: J Rauch, Systems Biology Ireland, University College Dublin, Belfield, Dublin D4, Ireland. Tel: +353 1716 6337; E-mail: jens.rauch@ucd.ie or W Kolch, Systems Biology Ireland, University College Dublin, Belfield, Dublin D4, Ireland. Tel: +353 1716 6931; E-mail: walter.kolch@ucd.ie Abbreviations: A-Raf, v-raf murine sarcoma 3611 viral oncogene homolog; Raf, rapidly accelerated fibrosarcoma; MAPK, mitogen-activated protein kinase; MST2, mammalian sterile 20-like kinase 2; HNSCC, head and neck squamous cell carcinoma; MEK, mitogen-activated protein kinase kinase; ERK, extracellular-signalregulated kinase; KSR2, kinase suppressor of Ras 2; FKBP, FK506-binding protein; EGFP, enhanced green fluorescent protein; EGF, epidermal growth factor; HRG, heregulin; RBD, Ras-binding domain

Received 21.2.15; revised 20.12.16; accepted 05.1.16; Edited by S Fesik; published online 19.2.16
} 
regulated by the cascade. ${ }^{26,27}$ Among the best-studied MAPK, scaffolds are the kinase suppressors of Ras proteins (KSR1 and KSR2), which were initially identified as a suppressor of an activated Ras phenotype in $D$. melanogaster $^{28}$ and C. elegans. ${ }^{29-31} \mathrm{KSR} 1$ and KSR2 bind to Raf, MEK, and ERK thereby controlling their phosphorylation and activation. $^{32,33}$ In $C$. elegans KSR1/2 have overlapping but also isotype-specific interactions and functions. ${ }^{34}$ In mammalian cells, KSR1 is crucial for oncogenic Ras signaling by binding to Raf-1 and B-Raf, ${ }^{35-37}$ whereas KSR2 recruits A-Raf rather than Raf-1 or B-Raf in response to TNF $a{ }^{38}$ In addition to MAPK components, KSR2 was shown to interact with AMPK thereby regulating energy intake and fatty acid oxidation. ${ }^{39,40}$ In humans, mutations of KSR2 are associated with obesity and insulin resistance. ${ }^{41}$ In addition, KSR2 regulates genes controlling adipocyte differentiation in white adipose tissue ${ }^{39}$ and is crucial for 1,25-dihydroxyvitamin $\mathrm{D}_{3}$-mediated monocytic differentiation of myeloid leukemia HL60 cells. ${ }^{42}$

Non-keratinized stratified squamous epithelium lines the external surface of tissues such as oral cavity, esophagus, rectum, and cervix, forming a protective barrier. During epithelial differentiation, epithelial progenitor cells of the highly proliferative basal membrane give rise to various cell types as they move upwards to build the multi-layered epithelium. Commitment and terminal differentiation not only involves regulation of specific genes and epigenetic control, but also induction of the apoptotic machinery for controlled caspase cleavage, enucleation, and internucleosomal DNA cleavage. ${ }^{43-45}$

We could show recently, that normal epithelia of the head and neck, colon, and liver show decreased levels of A-Raf in comparison to corresponding tumors ${ }^{16,21,46}$ and that this feature is regulated via A-Raf splice form selection involving the splice factors hnRNP A2 and $\mathrm{H}$. Although in tumors, splicing is shifted toward enhanced expression of the full-length A-Raf protein that sequesters MST2, normal epithelia, where hnRNP $\mathrm{H}$ and hnRNP A2 are low, express

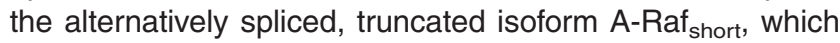
fails to control MST2. In addition, A-Raf short $_{\text {functions as a }}$ dominant-negative mutant due to its ability to bind to activated Ras activation and suppress MAPK activation. Thus, alternative A-Raf splicing acts as a safeguard against oncogenic transformation in normal epithelia.

Here, we report that A-Raf undergoes spatial regulation upon epithelial differentiation, re-localizing from the cytoplasm to the plasma membrane. We show that A-Raf cytoplasmatic localization is crucial for sequestration and inhibition of MST2 controlling the MST2 apoptotic pathway. We show that the MAPK scaffold protein KSR2 is crucial for the integrity of the A-Raf/MST2 complex and regulation of differentiation. We furthermore find that perturbation of either A-Raf localization or KSR2 expression causes apoptosis via MST2.

\section{Results}

A-Raf localizes to the plasma membrane during epithelial differentiation. We recently demonstrated that A-Raf strongly interacts with MST2 and inhibits MST2-mediated apoptosis. ${ }^{16,21}$ Both A-Raf and MST2 were localized at the mitochondria and cytoplasm in tumor cell lines as well as primary tumors. ${ }^{16}$ First, we confirmed our previously published data by immunohistochemistry showing a cytoplasmic expression of A-Raf in primary head and neck squamous cell carcinomas (Figure 1a). However, in non-malignant stratified, non-keratinized squamous epithelia of the same tissue origin (Figures 1b; Supplementary Figure S1A), A-Raf was differentially localized. Although in proliferating normal cells of the basal cell layer A-Raf was cytosolic, it moved to the plasma membrane during differentiation (Figure 1b). Interestingly, this relocalization coincides with the physiological nuclear pyknosis that takes place in the stratum spinosum. This differentiationassociated pyknosis involves activation of caspase-14, which like MST2 ${ }^{15}$ can be activated by Fas and TNFa signaling. ${ }^{47}$ These data suggest, that A-Raf changes localization in normal cells upon epithelial differentiation suggesting that A-Raf has different functions depending on its localization.

Plasma membrane-localized A-Raf loses its ability to inhibit MST2-mediated apoptosis. We next determined whether A-Raf localization was important for inhibition of MST2-mediated apoptosis. We stably expressed two versions of A-Raf: wt A-Raf, which is localized in the cytoplasm and A-Raf-CAAX, which constitutively localizes to the plasma membrane due to fusion with the CAAX motif from KRas $4 b^{48,49}$ (Figures $2 a$ and $c$ ). MST2 readily bound to wt A-Raf, but poorly bound to A-Raf-CAAX (Figure 2d). As expected from our previous studies, ${ }^{14,15}$ the interaction of Raf-1 with MST2 was disrupted by growth factors, while the interaction between wt A-Raf and MST2 was largely resistant (Figure 2d). These data indicate that A-Raf localization controls MST2 binding.

A-Raf is overexpressed in a variety of malignancies, including colon, ${ }^{16,21}$ head and neck, ${ }^{21}$ pancreatic ductal carcinomas, ${ }^{20}$ and astrocytic tumors, ${ }^{19}$ suggesting that tumor cells maintain high-level expression of A-Raf to prevent apoptosis by antagonizing the proapoptotic kinase MST2. We therefore examined, whether overexpression of plasma membrane-based A-Raf preserved this function, by activating MST2 using etoposide. ${ }^{16,50}$ Although overexpression of wt A-Raf inhibited MST2 activation (Figure 2e) and reduced apoptosis induced by etoposide (Figure 2f), A-Raf-CAAX could neither prevent activation of MST2 nor etoposidetriggered apoptosis (Figures $2 \mathrm{e}$ and $\mathrm{f}$ ). In addition, expression of neither wt nor membrane-targeted A-Raf influenced proliferation (Supplementary Figure S2A), ERK activation (Figure 2e; Supplementary Figures S2B-D), or oncogenic transformation (Supplementary Figure S2E), indicating that the localization-specific regulation by A-Raf selectively affects the MST2 but not the ERK pathway.

A dynamic recruitment of Raf proteins from the cytoplasm to the plasma membrane is well described upon activation of Ras. ${ }^{51-54}$ We therefore examined, whether dynamic changes of A-Raf localization impact on MST2 binding. For this purpose, we used the rapalogue (AP21967)-inducible heterodimerization system, which permits the efficient and selective cross-linking of FRB and FKBP-tagged proteins, ${ }^{55,56}$ We co-expressed a flag-tagged FRB A-Raf 

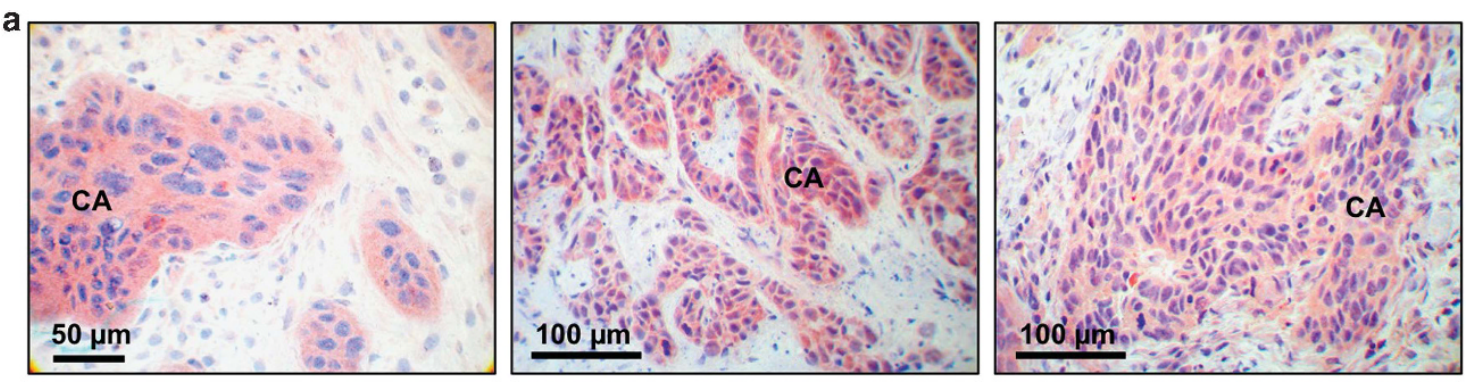

b

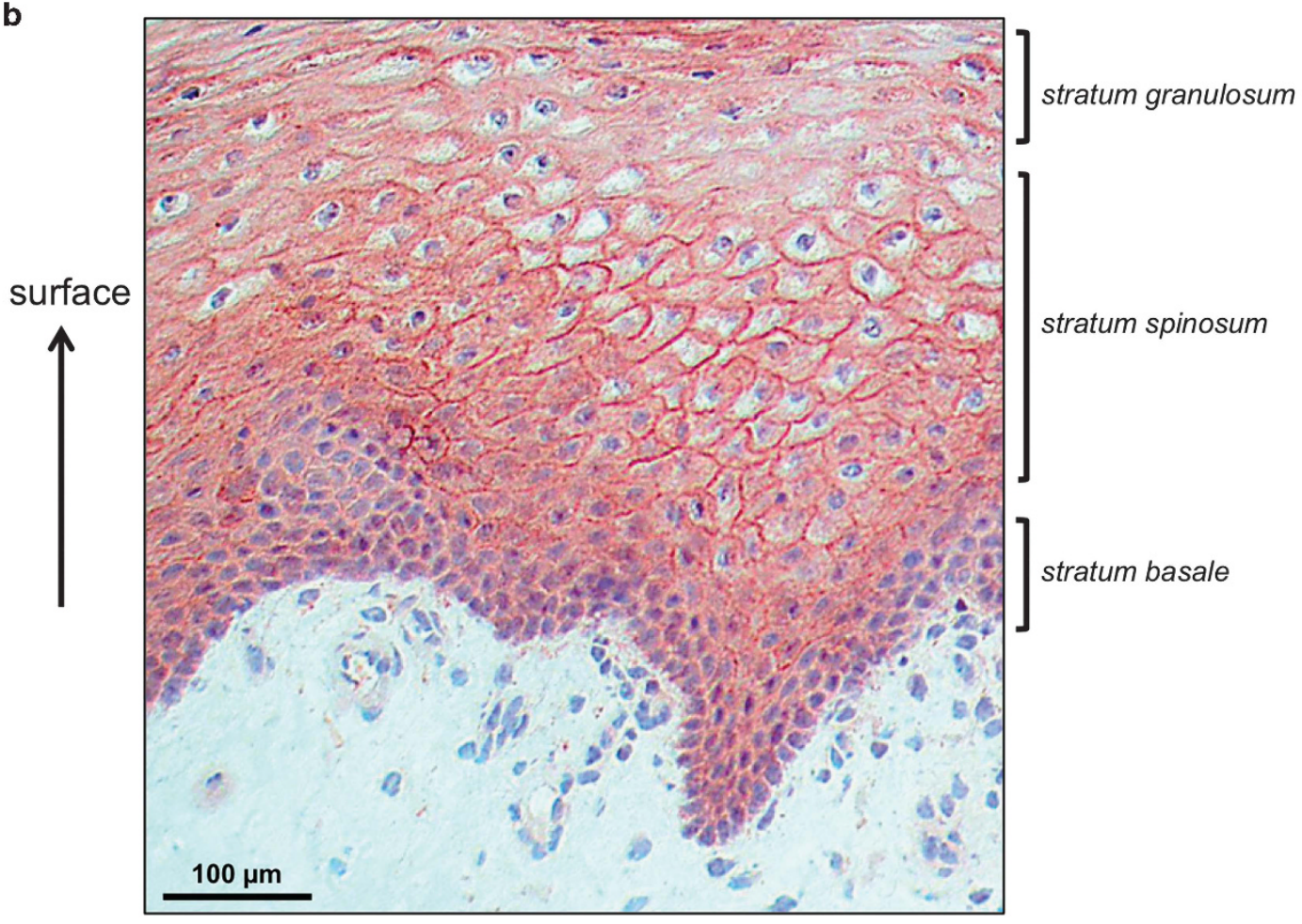

Figure 1 A-Raf localizes to the plasma membrane during epithelial differentiation. (a) A-Raf expression was detected in carcinoma tissues of HNSCC, and (b) non-malignant stratified, non-keratinized squamous epithelia of the same tissue origin. Immunohistochemistry was performed on cryosections of human tissue specimens

fusion (FRB-A-Raf-flag) with a tandem FKBP domain construct (Myr.-2xFKBP-HA) that was targeted to the plasma membrane by an $\mathrm{N}$-terminal myristoylation tag (Figures $3 \mathrm{a}$ and b). Although FRB-A-Raf-flag localized to the cytoplasm in HeLa cells, addition of AP21967 led to membrane recruitment of A-Raf due to heterodimerization with Myr.-2xFKBP-HA (Figure 3c; Supplementary Figure S3). The heterodimerization and membrane recruitment of A-Raf occurs over a wide concentration range and is stable for at least $8 \mathrm{~h}$ allowing co-immunoprecipitation of the FRB-A-Raf-flag and Myr.-2xFKBP-HA proteins (Supplementary Figure S3). In contrast, MST2 localization does not change upon AP21967induced re-localization of A-Raf (Figure 3c). Dynamic membrane recruitment of $A$-Raf leads to the disruption of the A-Raf-MST2 complex (Figure 3d). We next asked whether dynamic A-Raf re-localization was important for inhibition of MST2-mediated apoptosis (Figure 3e). Cytoplasmic A-Raf fully counteracts etoposide-induced MST2 activation and apoptosis as shown by cleavage of caspase 3 and poly
(ADP-ribose) polymerase (PARP), and the activation of PUMA expression. In contrast, when A-Raf was re-localized to the membrane by AP21967 treatment, it failed to inhibit MST2 activation and downstream apoptosis. Again, localization of A-Raf did not impact on bulk ERK activation. Taken together, these results suggest that A-Raf cytoplasmic localization is crucial for MST2 binding, inhibition, and regulation of MST2mediated apoptosis.

A-Raf re-localizes at the plasma membrane during mammary differentiation. We next investigated the mechanism underlying re-localization of A-Raf and regulation of MST2-mediated apoptosis during differentiation processes in an in vitro differentiation system. MCF7 cells, derived from breast adenocarcinoma, can undergo phenotypic changes including lipid accumulation, which can be quantified as a measure of differentiation (Figure 4a). ${ }^{57-62}$ We therefore stably overexpressed A-Raf fused to EGFP in MCF7 cells and induced differentiation by serum starvation and 

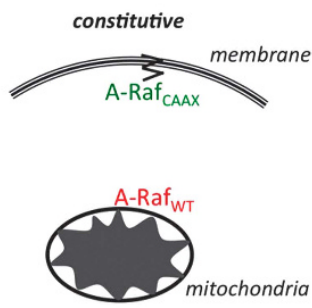

C

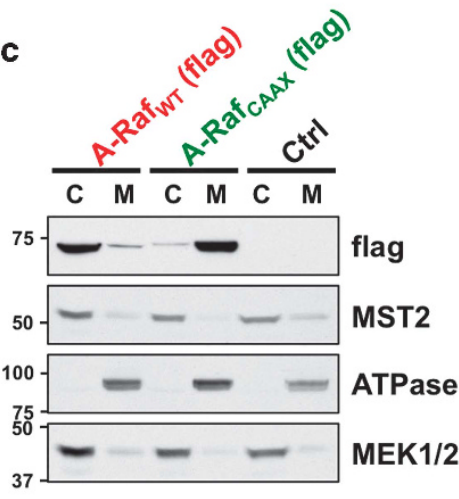

e

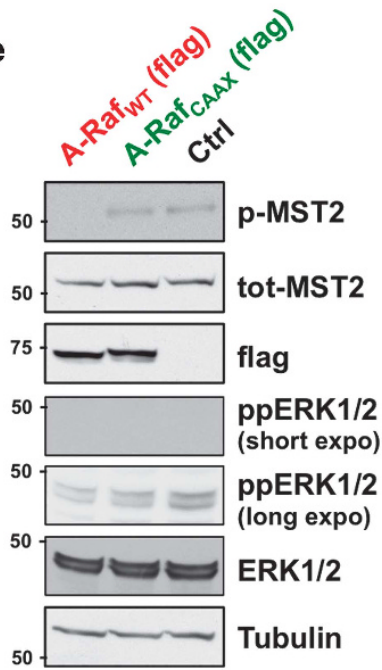

\author{
Constructs
}

flag A-Raf

flag A-Raf CAAX

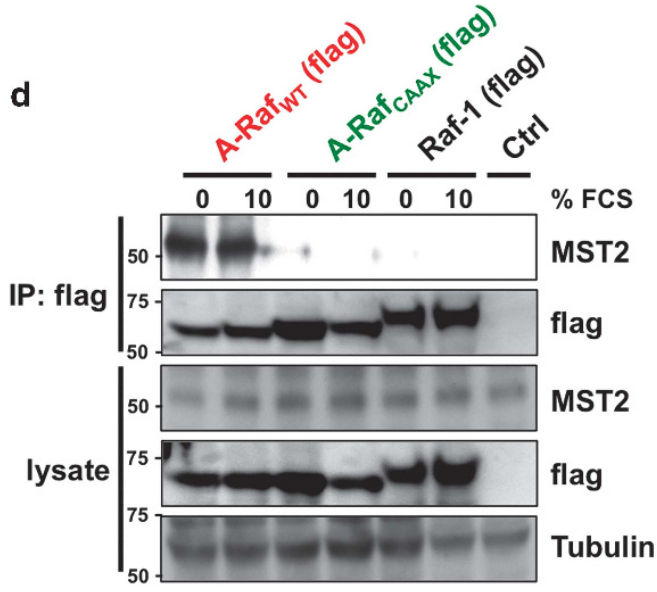

f

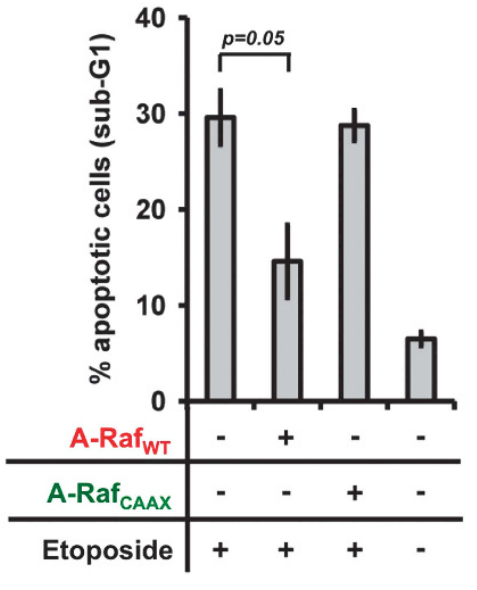

Figure 2 Plasma membrane-localized A-Raf loses its ability to inhibit MST2-mediated apoptosis. (a and $\mathbf{b}$ ) HeLa cells were transfected with either wild-type A-Raf or A-Raf fused with the CAAX motif from KRas4b. (c) Subcellular fractionation demonstrated the localization of A-Raf and MST2 by western blot. MEK1/2 and ATPase were used as subcellular markers for the cytoplasm $(\mathrm{C})$ and membrane $(\mathrm{M})$ fractions, respectively. (d) Flag-tagged A-Raf or Raf-1 constructs were expressed in HeLa cells. Following serum starvation or stimulation with FCS, protein complexes were immunoprecipitated with anti-flag antibody, and proteins were detected by immunoblotting with anti-flag or anti-MST2 antibodies. Tubulin served as a protein loading control. (e) Equal amounts of flag-tagged A-Raf constructs were expressed in HeLa cells. Following serum starvation, lysates were probed for the indicated proteins by immunoblotting. (f) Equal amounts of flag-tagged A-Raf constructs were expressed in HeLa cells as in (e). Following serum starvation and treatment with $10 \mu \mathrm{M}$ etoposide $24 \mathrm{~h}$ post transfection, the proportion of apoptotic cells was assessed on measuring DNA fragmentation by flow cytometry $72 \mathrm{~h}$ post transfection. Error bars indicate S.D. of three individual experiments

concomitant stimulation with heregulin ${ }^{57,62}$ using epidermal growth factor (EGF) as control. Although EGFP alone localizes ubiquitously in the cell and independently of the stimulus (Figure 4b, upper panel), EGFP-A-Raf localizes to the cytoplasm under growing conditions (10\% FCS; Supplementary Figure S4A), or in cells treated with EGF (Figure 4b). Stimulation with heregulin induces an accumulation of EGFP-A-Raf at the plasma membrane (Figures $4 \mathrm{~b}$ and c) at regions reminiscent of tight junctions. Again, stable overexpression of EGFP-A-Raf inhibits activation of MST2
(Figure 4d), but has no impact on bulk ERK activation (Figure 4d), cell proliferation (Supplementary Figure S4B), AKT and ERK signaling dynamics except that ERK activation at $5 \mathrm{~min}$ is dampened (Supplementary Figure S4C).

To confirm the imaging data and quantify the subcellular re-distribution of endogenous A-Raf upon differentiation of MCF7 cells, cytosolic and membrane fractions were isolated. Although in control and EGF-treated cells, EGFP-A-RafEGFP and MST2 were found in the cytoplasmic fraction, stimulation with heregulin increased A-Raf in the membrane 
a

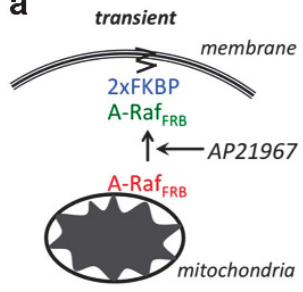

b

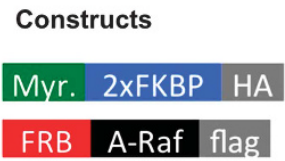

c

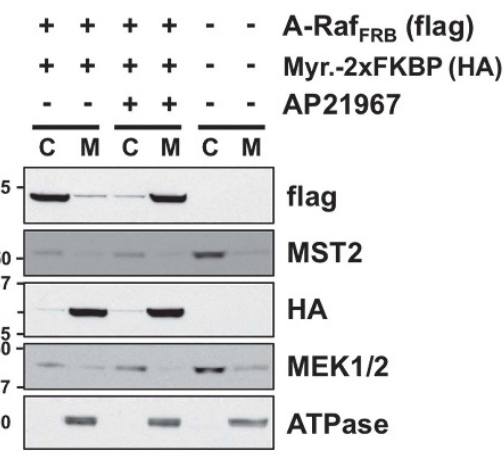

e

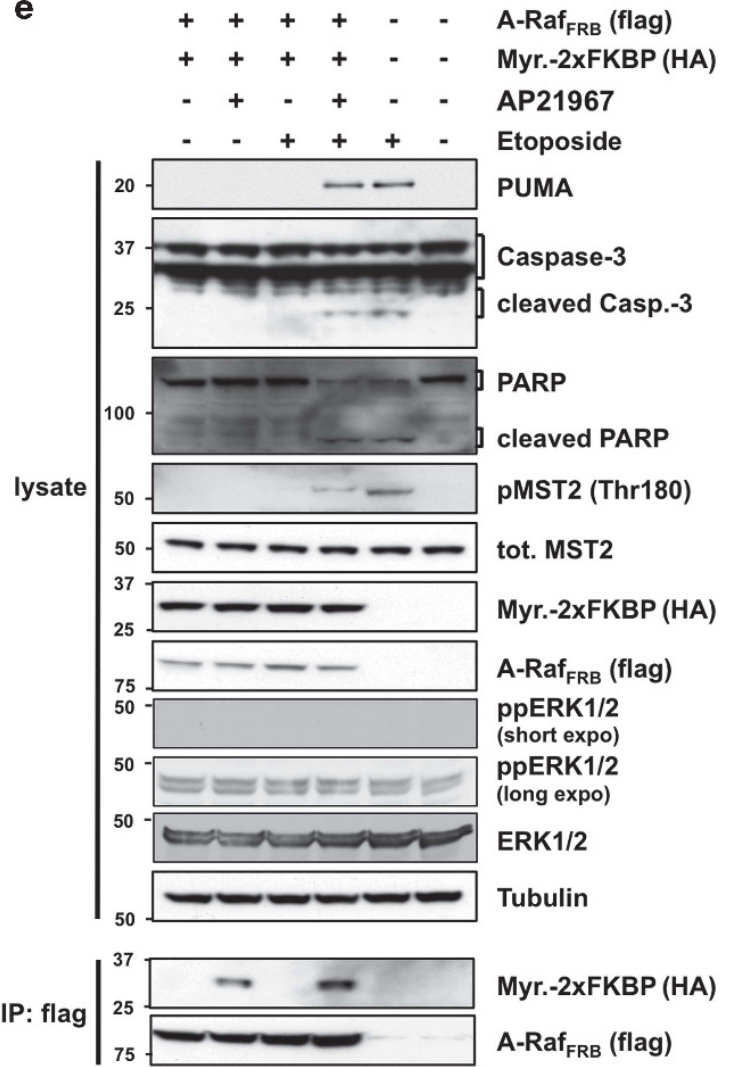

Figure 3 Dynamic re-localization of A-Raf induces MST2-mediated apoptosis. (a and $\mathbf{b}$ ) For rapalogue-induced recruitment of A-Raf to the plasma membrane, HeLa cells were co-transfected with the A-Raf recruitment fusion construct (FRB-A-Raf-flag) and myristoylated tandem FK506-binding protein domain (Myr--2xFKBP-HA). (c) Twenty-four hours post transfection, cells were treated with the $500 \mathrm{nM} \mathrm{AP21967}$ as indicated for $1 \mathrm{~h}$, and subcellular fractionation demonstrated the localization of A-Raf, MST2, and FKBP by western blot. MEK1/2 and ATPase were used as subcellular markers for the cytoplasm (C) and membrane (M) fractions, respectively. (d) HeLa cells were co-transfected with FRB-A-Raf-flag and Myr.-2xFKBP-HA, and $24 \mathrm{~h}$ post transfection, cells were treated with the $500 \mathrm{nM}$ AP21967 as indicated. Protein complexes were isolated with anti-HA, antiflag, or anti-MST2 antibodies, respectively, and proteins were detected by immunoblotting with anti-HA, anti-flag, or anti-MST2 antibodies. Tubulin served as a protein loading control. (e) HeLa cells were co-transfected with FRB-A-Raf-flag and Myr-2xFKBP-HA, and $24 \mathrm{~h}$ post transfection, cells were treated with the $500 \mathrm{nM}$ AP21967 and $10 \mu \mathrm{M}$ etoposide as indicated. Protein complexes were isolated $24 \mathrm{~h}$ later with anti-flag antibody and proteins detected by immunoblotting with anti-HA and anti-flag antibodies. Lysates were probed for expression of PUMA, MST2, activated MST2 (Thr180), activated ERK1/2, PARP, and caspase 3 cleavage. Tubulin served as a protein loading control

fraction (Figure 5a). Endogenous A-Raf and MST2 showed the same changes in distribution (Figure $5 b$ ), corroborating the re-distribution of endogenous A-Raf to the membrane during differentiation. The re-localization of A-Raf during heregulin-mediated differentiation of MCF7 cells resulted in activation of MST2 (Figures $4 \mathrm{c}$ and $5 \mathrm{c}$ ) and activation of caspase 8 (Figure $5 \mathrm{c}$ ), which could be reduced by A-Raf overexpression (Figure $5 \mathrm{c}$ ).

Taken together, these data suggest that A-Raf re-localizes to the plasma membrane during heregulin-induced differentiation of MCF7 cells, resulting in activation of MST2 and caspases. 
a
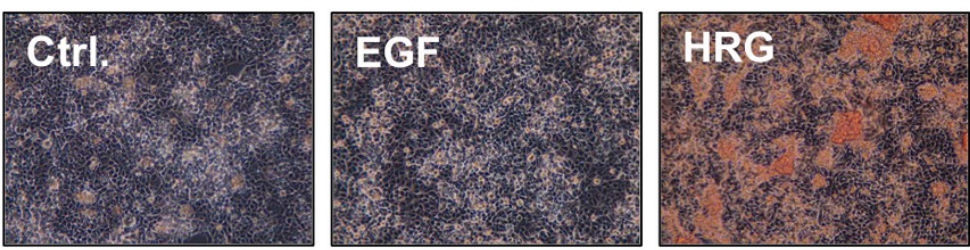

b
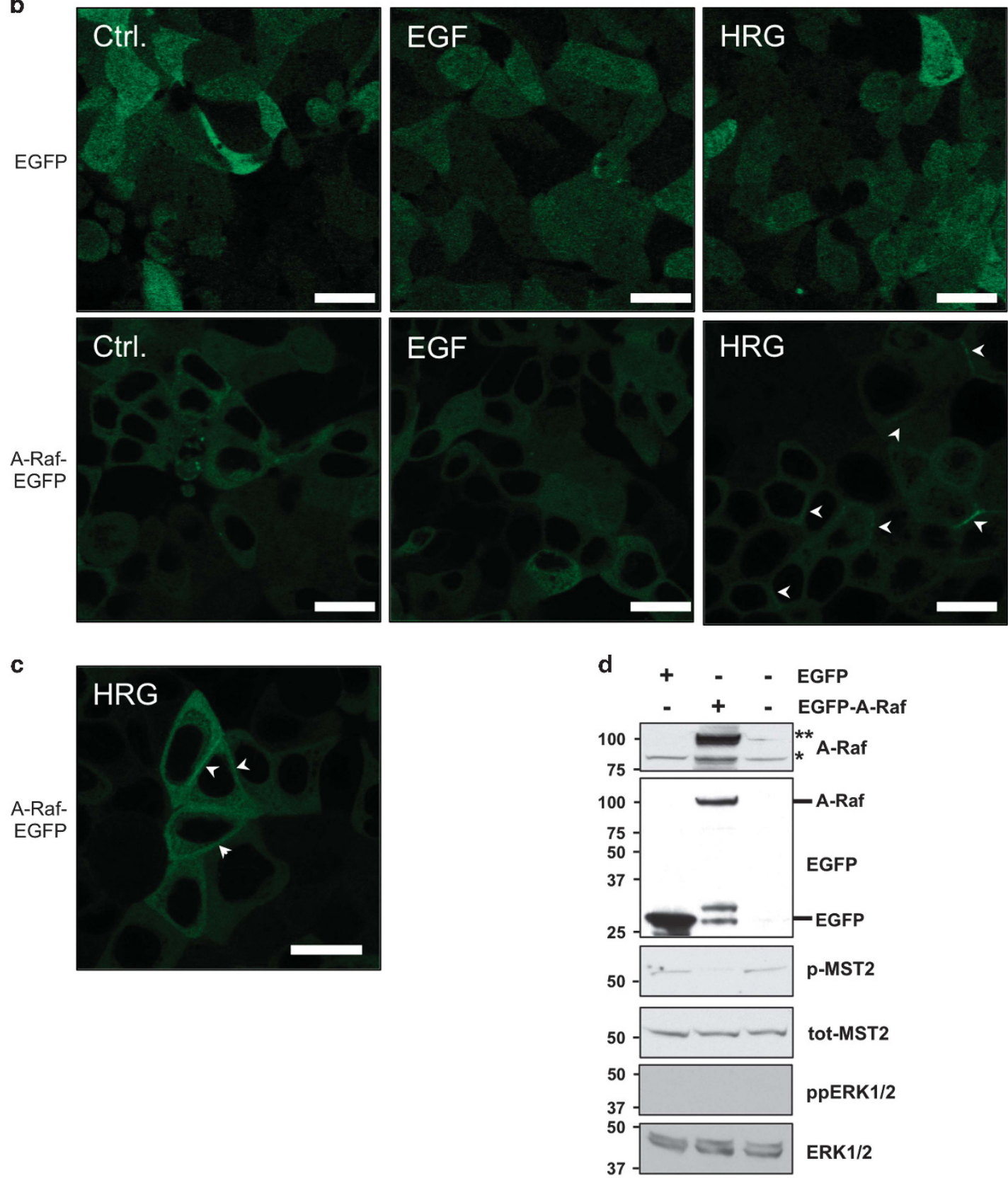

Figure 4 A-Raf re-localizes to the plasma membrane during mammary differentiation. (a) Heregulin-mediated differentiation of MCF7 cells. MCF7 cells were seeded in standard 24-well plates $\left(0.4 \times 10^{6}\right.$ per well) and serum-starved ( $1 \%$ FCS) $24 \mathrm{~h}$ prior to stimulation with either $10 \mathrm{nM}$ EGF or $2 \mathrm{nM}$ heregulin. After 6 days, cells were fixed and stained with Oil Red. Shown are bright field images of indicated cells. (b and c) MCF7 cells were seeded in standard 24 -well plates $\left(0.4 \times 10^{6}\right.$ per well) and serum-starved ( $1 \%$ FCS) $24 \mathrm{~h}$ prior to stimulation with either $10 \mathrm{nM}$ EGF or $2 \mathrm{nM}$ heregulin. After 6 days, A-Raf fused to EGFP or EGFP alone were visualized in live cells using confocal microscopy. White arrows indicate membrane localization of A-Raf-EGFP. Scale bar, $20 \mu \mathrm{m}$. (d) Cells from (a) were lysed and probed for expression of A-Raf, EGFP, activated ERK1/2, MST2, and activated MST2 using western blot. ERK1/2 served as a protein loading control. *Endogenous A-Raf and ${ }^{* *}$ EGFP-A-Raf 
a

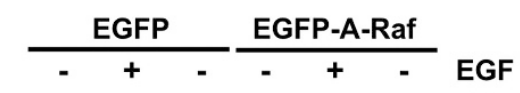

$-\frac{-}{C}+\frac{-}{C M}+\frac{-}{C}+\mathrm{HRG}$
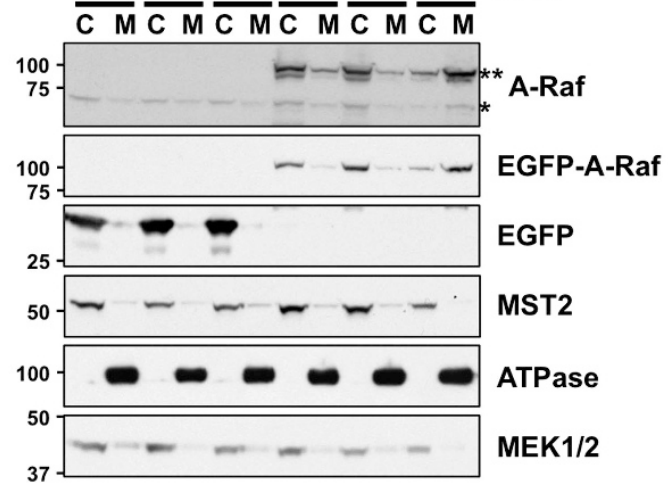

c

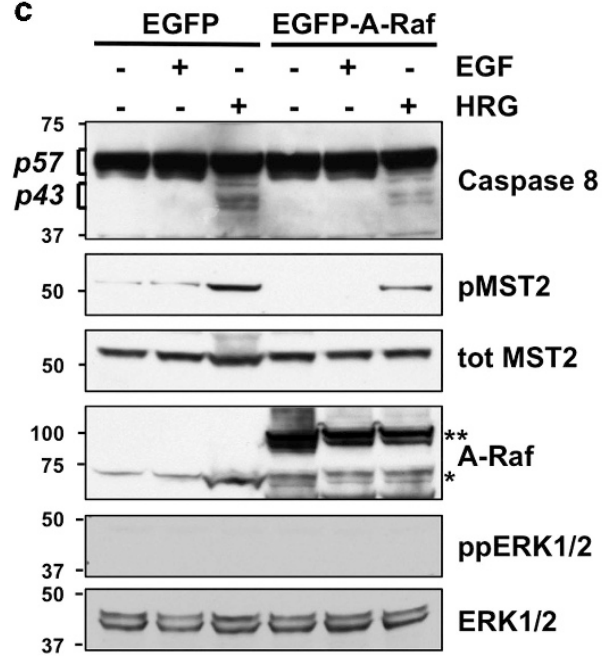

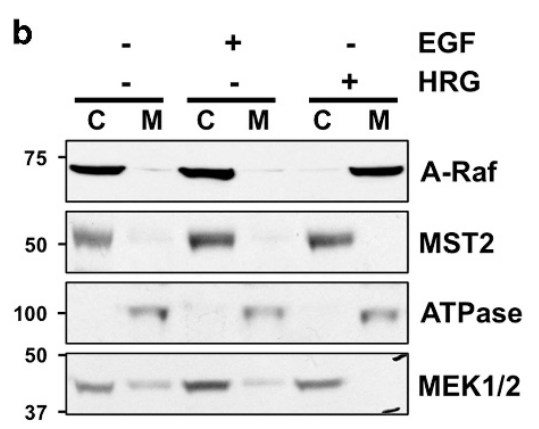

Figure 5 Re-localization of A-Raf during mammary differentiation induces MST2-mediated apoptosis. (a) MCF7 cells stably expressing EGFP-A-Raf or EGFP alone were seeded in standard 24 -well plates $\left(0.4 \times 10^{6}\right.$ per well) and serum-starved ( $\left.1 \% \mathrm{FCS}\right) 24 \mathrm{~h}$ prior to stimulation with either $10 \mathrm{nM} \mathrm{EGF}$ or $2 \mathrm{nM}$ heregulin. After 6 days, subcellular fractionation demonstrated the localization of A-Raf-EGFP, EGFP, and MST2 by western blot. MEK1/2 and ATPase were used as subcellular markers for the cytoplasm (C) and membrane (M) fractions, respectively. ${ }^{*}$ Endogenous A-Raf and ${ }^{* *}$ EGFP-A-Raf. (b) MCF7 cells were seeded in standard 24 -well plates $\left(0.4 \times 10^{6}\right.$ per well) and serum-starved (1\% FCS) $24 \mathrm{~h}$ prior to stimulation with either $10 \mathrm{nM}$ EGF or $2 \mathrm{nM}$ heregulin. After 6 days, subcellular fractionation demonstrated the localization of endogenous A-Raf and MST2 by immunoblot. MEK1/2 and ATPase were used as subcellular markers for the cytoplasm (C) and membrane (M) fractions, respectively. (c) MCF7 cells stably expressing EGFP-ARaf or EGFP alone were seeded in standard 24-well plates $\left(0.4 \times 10^{6}\right.$ per well) and serum-starved ( $\left.1 \% \mathrm{FCS}\right) 24 \mathrm{~h}$ prior to stimulation with either $10 \mathrm{nM}$ EGF or $2 \mathrm{nM}$ heregulin.

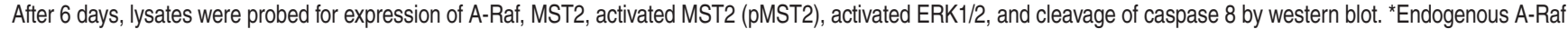
and ${ }^{*}$ EGFP-A-Raf

A-Raf enhances heregulin-mediated differentiation of MCF7 cells. In an independent study, we identified A-Raf among other factors in a proteomic screen designed to probe for changes in protein expression in epithelial-tomesenchymal transition (EMT) of MDCK cells. ${ }^{63}$ We could demonstrate that inhibiting the MST2 pathway by overexpression of A-Raf promotes HGF-induced EMT.

On the basis of these data, we hypothesized that A-Raf function might be instrumental for the differentiation process. Therefore, we used the MCF7 cells, which stably overexpress EGFP-A-Raf or EGFP alone and quantified differentiation in response to heregulin. Although no difference in lipid accumulation could be detected between control cells and cells expressing EGFP, A-Raf overexpression increased differentiation as measured by lipid droplet accumulation by
33\% (Figure 6a). Decreasing A-Raf expression by transfection with specific siRNA modestly, but significantly, reduced differentiation (Figure $6 \mathrm{~b}$ ) indicating that the effect is indeed mediated by A-Raf. In order to corroborate that the measured effects are not due to clonal selection of the stable cell line overexpressing EGFP-fused A-Raf, we repeated the experiments with a different plasmid set (pcDNA3-based) and transient transfection. Transient overexpression of wt A-Raf or a kinase-dead version of A-Raf (K336M) increased heregulinmediated differentiation by 18 and $29 \%$, respectively (Figure 6c). These data suggest that A-Raf promotes differentiation independently of A-Raf kinase activity suggesting that this effect is not mediated through the ERK pathway but through inhibition of MST2, which does not require A-Raf kinase activity. 
The scaffold kinase suppressor of Ras 2 (KSR2) regulates A-Raf localization and MST2 activity. We next investigated the mechanism underlying the re-localization of A-Raf during differentiation. A-Raf was shown to interact with a plethora of other proteins, ${ }^{2,64}$ including scaffold proteins regulating ERK signaling. ${ }^{25}$ Recently, it was suggested that the scaffold kinase suppressor of Ras 2 (KSR2) mediates A-Raf signaling, while a close homolog, KSR1, would facilitate Raf-1-mediated ERK signaling. ${ }^{38}$ On the basis of these data, we hypothesized that KSR2 may function as a

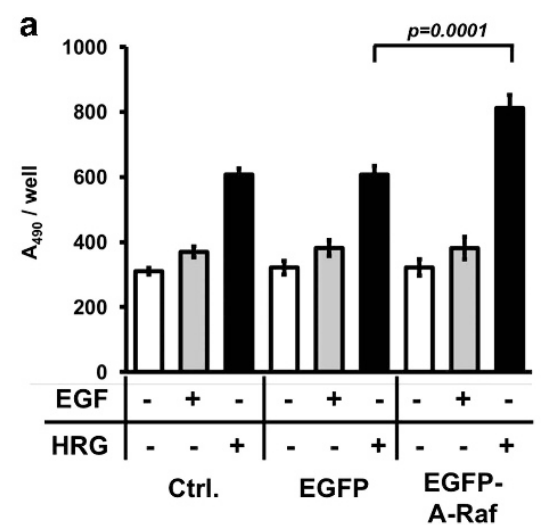

b
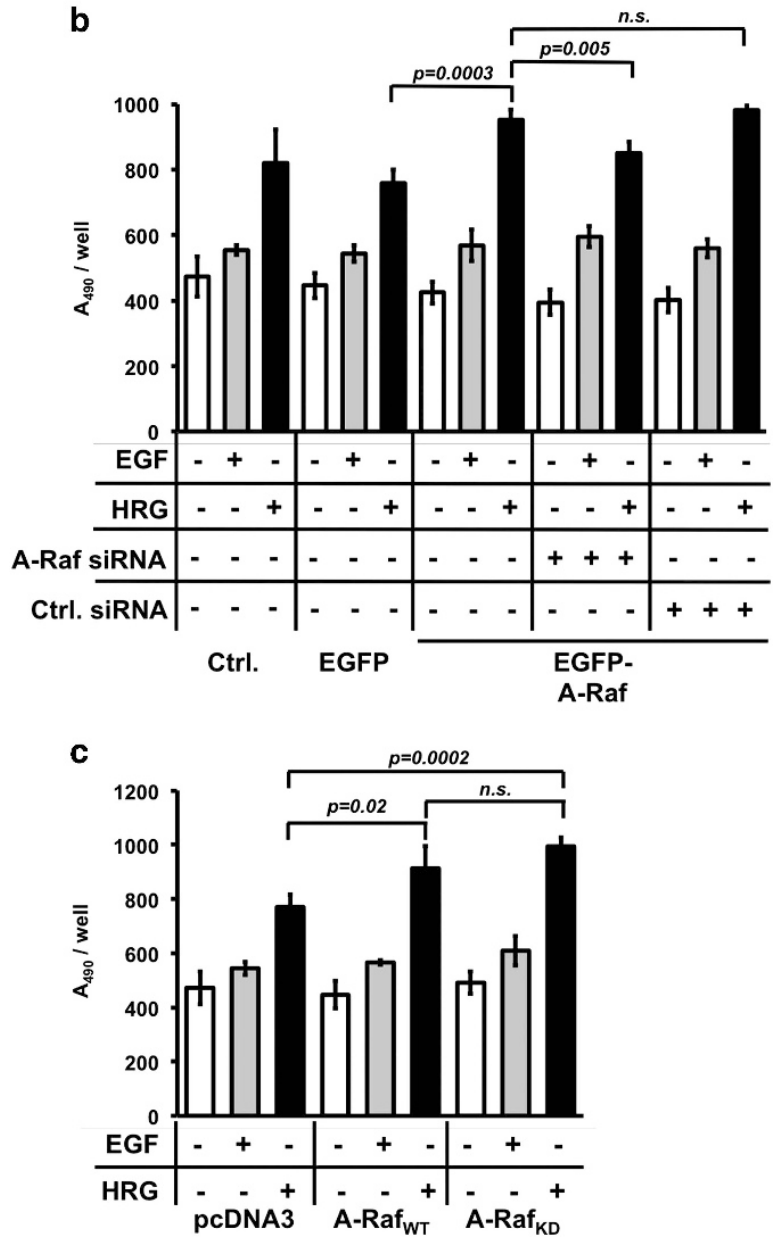

scaffold to control A-Raf localization and its ability to regulate MST2 activity. First, we confirmed that KSR2 can interact with A-Raf and MST2, while no interaction between A-Raf and KSR1 could be observed (Figure 7a). ${ }^{38}$ We then determined, if KSR2 expression is regulated during heregulin-mediated differentiation of MCF7 cells. KSR2 expression is downregulated during differentiation, while the expression of KSR1, A-Raf, and its upstream regulator hnRNP $\mathrm{H}^{16,21}$ is not changed (Figure $7 \mathrm{~b}$ ). Monitoring KSR2 expression over a timecourse of differentiation, we found that KSR2 expression is lost 5 days post induction with heregulin (Supplementary Figure S5), suggesting that KSR2 loss represents a late event during MCF7 differentiation.

We next determined whether the changes in A-Raf localization and regulation of MST2 are dependent of KSR2 (Figure 7c). Knocking down KSR2 by siRNA induced MST2 activation in serum-starved MCF7 cells. Interestingly, knocking down KSR2 also abolished the interactions between MST2 and A-Raf, suggesting that KSR2 is required as a scaffold for the MST2 interaction with A-Raf, or that it directs A-Raf to a subcellular compartment that enables this interaction. Importantly, KSR2 depletion causes a re-localization of A-Raf from the cytosol to the membrane as shown by cell fractionation (Figure 7c). In addition, siRNA-mediated knockdown of A-Raf does abolish the interaction between KSR2 and MST2 (Figure 7d), suggesting that MST2 binds directly to A-Raf and not KSR2, and that A-Raf seems to be crucial to keep the trimeric complex intact.

Taken together, these data suggest a model where the scaffold KSR2 is required for the sequestration and inhibition of MST2 by A-Raf in tumor and proliferating cells (Figure 7e). Loss of KSR2 during differentiation results in A-Raf re-localization to the plasma membrane, the disruption of the anti-apoptotic A-Raf-MST2 complex and activation of the MST2 pathway.

\section{Discussion}

Spatial regulation of Raf kinases within the cellular compartments is regulated in a highly dynamic and concerted manner. ${ }^{2}$ In growth factor-deprived cells, Raf- 1 is localized in the cytoplasm in an inactive state. Here, Raf proteins are

Figure 6 A-Raf induces heregulin-mediated differentiation of MCF7 cells. (a) MCF7 cells stably expressing EGFP-A-Raf or EGFP alone or control cells were seeded in standard 24-well plates $\left(0.4 \times 10^{6}\right.$ per well), and serum-starved ( $1 \%$ FCS) $24 \mathrm{~h}$ prior to stimulation with either $10 \mathrm{nM}$ EGF or $2 \mathrm{nM}$ heregulin. After 6 days, cells were fixed and stained with Oil Red, which was extracted with isopropanol, and quantified measuring light absorbance. Error bars indicate S.D. of four individual experiments. (b) MCF7 cells stably expressing EGFP-A-Raf or EGFP alone were seeded in standard 24-well plates $\left(0.4 \times 10^{6}\right.$ per well), co-transfected with either control siRNA or human A-Raf siRNA as indicated, and serum-starved (1\% FCS) $24 \mathrm{~h}$ prior to stimulation with either $10 \mathrm{nM}$ EGF or $2 \mathrm{nM}$ heregulin. After 6 days, cells were fixed and stained with Oil Red, which was extracted with isopropanol, and quantified measuring light absorbance. Error bars indicate S.D. of four individual experiments. (c) MCF7 cells were seeded in standard 24 -well plates $\left(0.4 \times 10^{6}\right.$ per well), transiently transfected with control plasmid (pcDNA3), wild-type A-Raf or a kinase-dead version of A-Raf (KD), and serum-starved (1\% FCS) $24 \mathrm{~h}$ prior to stimulation with either $10 \mathrm{nM}$ EGF or $2 \mathrm{nM}$ heregulin. After 6 days, cells were fixed and stained with Oil Red, which was extracted with isopropanol, and quantified measuring light absorbance. Error bars indicate S.D. of four individual experiments 
a
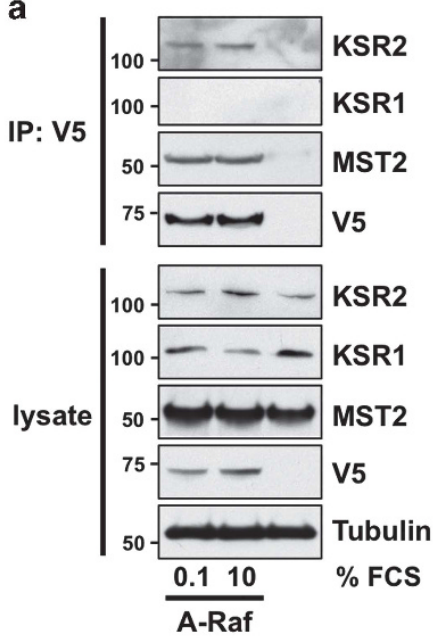

(V5)

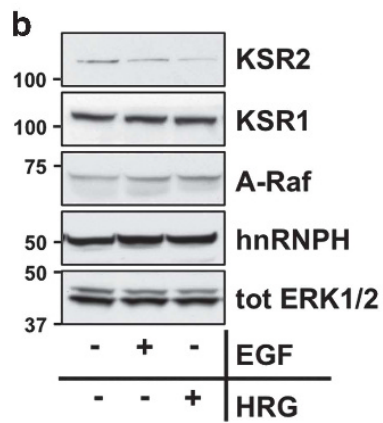

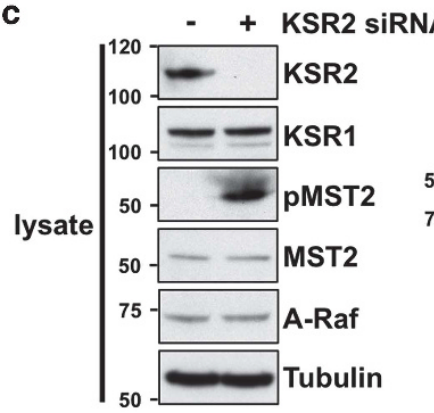

d

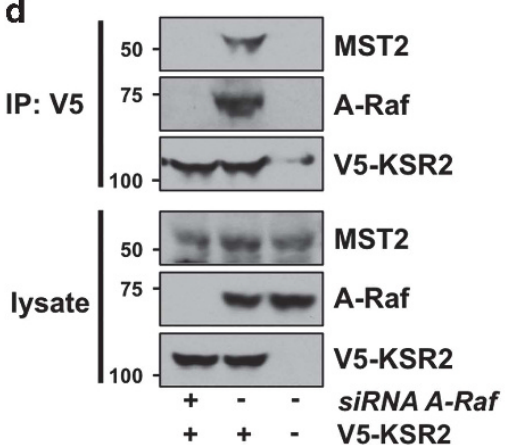

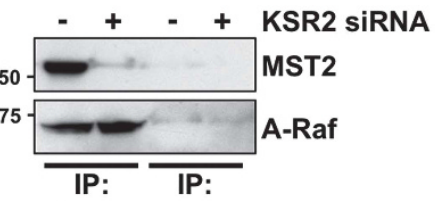

A-Raf isotype
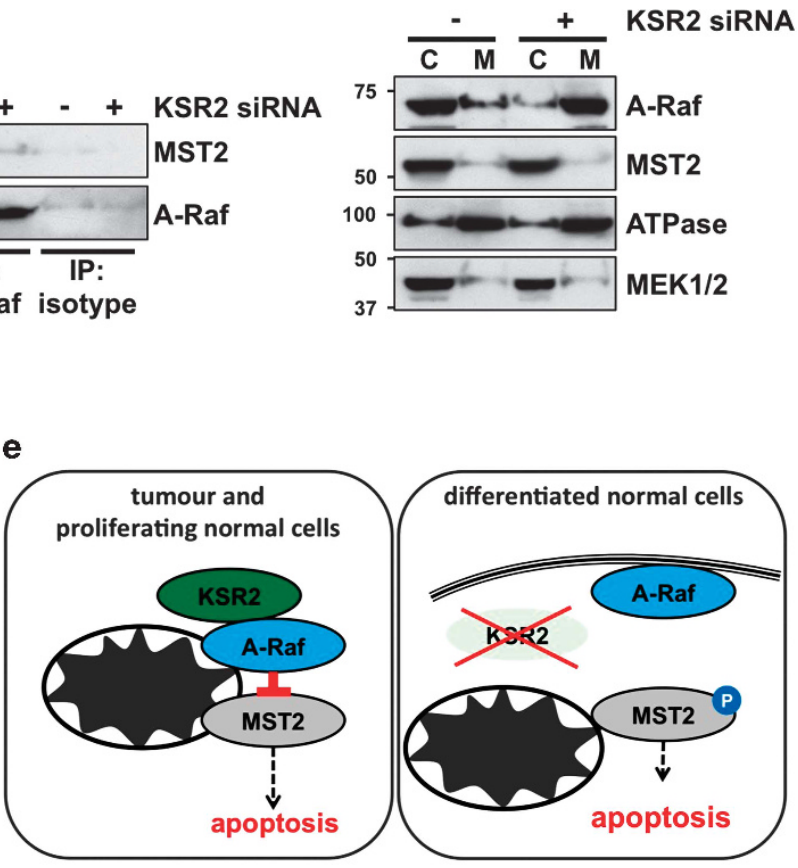

Figure 7 The scaffold kinase suppressor of Ras 2 (KSR2) regulates A-Raf localization and MST2 activity. (a) V5-tagged A-Raf was expressed in MCF7 cells. Following serum starvation or stimulation with FCS, protein complexes were immunoprecipitated with anti-V5 antibody, and proteins were detected by immunoblotting with anti-V5, anti-MST2, antiKSR1, and anti-KSR2 antibodies. Tubulin served as a protein loading control. (b) MCF7 cells were seeded in standard 24-well plates $\left(0.4 \times 10^{6}\right.$ per well) and serum-starved (1\% FCS) $24 \mathrm{~h}$ prior to stimulation with either $10 \mathrm{nM}$ EGF or $2 \mathrm{nM}$ heregulin. After 6 days, lysates were probed for expression of hnRNP H, A-Raf, KSR1, and KSR2. ERK1/2 served as a protein loading control. (c) Left panel: MCF7 cells were transfected with either control siRNA or KSR2 siRNA as indicated and probed for A-Raf, MST2, pMST2, KSR1, and KSR2 by western blot. Tubulin served as a protein loading control. Middle panel: upon transfection with either control siRNA or human KSR2 siRNA, endogenous A-Raf was immunoprecipitated and proteins were detected by immunoblotting with anti-A-Raf and anti-MST2 antibodies. Right panel: upon transfection with either control siRNA or human KSR2 siRNA, subcellular fractionation demonstrated the localization of endogenous A-Raf and MST2 by immunoblot. MEK1/2 and ATPase were used as subcellular markers for the cytoplasm (C) and membrane (M) fractions, respectively. (d) V5-tagged KSR2 was expressed in MCF7 cells in combination with siRNA-mediated knockdown of A-Raf. Following serum starvation, protein complexes were immunoprecipitated with anti-V5 antibody, and proteins were detected by immunoblotting with anti-V5, anti-MST2, and antiARAF antibodies. (e) Hypothesis and model for KSR2-mediated regulation of the A-Raf-MST2 complex. In tumor cells and highly proliferating normal cells, high levels of KSR2 ensure mitochondrial expression of A-Raf to keep MST2 in an inactive state thereby providing an anti-apoptotic milieu. In contrast, in differentiated normal cells, KSR2 expression is lost leading to A-Raf localization at the membrane, disruption of the complex with MST2, and induction of MST2-mediated apoptosis

stabilised in a closed conformation by binding to 14-3-3 dimers. Upon activation through growth factors, dephosphorylation at the cell membrane by PP2A and PP1 phosphatases releases 14-3-3 from Raf thereby enabling Ras binding and membrane recruitment. ${ }^{51,53,65-67}$ However, due to the exchange of an arginine for a lysine at position 22 in its RBD and a non-conserved tyrosine 296 in the N-region, A-Raf is only weakly activated by oncogenic $\mathrm{H}-\mathrm{Ras}^{9,68}$ In addition, 
several phosphorylation sites between amino acids 248 and 267 seem to facilitate A-Raf dissociation from the plasma membrane. ${ }^{69}$ This electrostatic destabilization together with low kinase activity toward MEK seems to direct A-Raf to other subcellular compartments. We could demonstrate recently, that A-Raf localizes to the mitochondria in tumor cell lines as well as primary tumors, where it binds the proapoptotic kinase MST2 and suppresses its activation and MST2-induced apoptosis. ${ }^{16,21}$ Here, we demonstrate that A-Raf localization is regulated upon epithelial differentiation. Although in highly proliferating cells of the basal cell layer of non-malignant stratified, non-keratinized squamous epithelia, A-Raf localized to the cytoplasm and mitochondria, differentiated noncarcinogenic cells of head and neck epithelia expressed A-Raf at the plasma membrane. We observe a sharp demarcation between basal cells expressing A-Raf at the cytoplasm or mitochondria and the juxtaposed suprabasal cells with A-Raf at the plasma membrane. Our results suggest a thorough re-localization of A-Raf, which correlates with morphological transition from undifferentiated stem cells to terminal differentiation. Intriguingly, in the cell models used, this spatial regulation of A-Raf correlates with its anti-apoptotic function. Although cytoplasmic and mitochondrial A-Raf keeps anti-apoptotic signaling via MST2 in check, plasma membrane-standing A-Raf is not capable of MST2 binding and inactivation.

Interestingly, A-Raf expression and anti-apoptotic function is consistent with our previous reports that the splice factor hnRNP $\mathrm{H}$ controlling A-Raf splicing is highly expressed in basal cells but get lost during epithelial differentiation. ${ }^{70}$

Furthermore, we could demonstrate that the scaffold protein KSR2 is crucial for the A-Raf-MST2 complex. KSR2 expression is lost during epithelial differentiation thereby releasing A-Raf to the plasma membrane leading to activation of MST2 and subsequent apoptosis. Although previous reports demonstrated interaction between A-Raf and KSR2 only in response to $\mathrm{TNF} a,{ }^{38}$ we observe interaction also in quiescent cells and upon stimulation with EGF. KSR2 is also known to bind AMPK mediating its stimulatory effects on glucose uptake and fatty acid oxidation, ${ }^{39}$ suggesting that A-Raf may play a direct role in the cross-talk between apoptosis (MST2), energy homeostasis (AMPK), MAPK signaling, and glucose metabolism by binding and inhibiting pyruvate kinase M2 (PKM2). ${ }^{71,72}$

In addition to its functional role of regulating MST2-mediated apoptosis in differentiation, A-Raf expression also correlates with the extent of differentiation in the described MCF7 cell model. Here, overexpression of A-Raf independent of kinase activity increases differentiation, which is in line with an independent study from our group, ${ }^{63}$ where A-Raf overexpression inhibits the MST2/Hippo pathway thereby promoting HGF-induced EMT in MDCK cells. This is also in line with previous reports, where A-Raf expression correlated with adipocyte $^{23}$ and myogenic ${ }^{24}$ differentiation.

Although our results demonstrate a causal role and spatial regulation of A-Raf during epithelial differentiation, its target MST2 is stably localized in the cytoplasm. The MST2 tumor suppressor pathway is a master regulator of proliferation, cell death, and cellular differentiation controlling normal tissue development, organ size, and cancer. ${ }^{73-75}$ Activation of the MST2/Hippo pathway leads to the activation and cytoplasmic retention of the transcriptional coactivators YAP/TAZ and the subsequent junction formation in epthelial cells through interaction with members of the angiomotin (AMOT) family. ${ }^{76-78}$ The involvement of the Hippo/MST2 pathway in epithelial behavior and downstream processes were recently reviewed. ${ }^{79}$ MST2 itself and its closest isoform MST1 were shown to be crucial for 1,25-dihydroxyvitamin $D_{3}$-mediated monocytic differentiation of myeloid leukemia HL60 cells, ${ }^{42}$ control the downstream kinase YAP to control pancreatic acinar differentiation mice, ${ }^{80}$ regulate trophoblast differentiation via the transcription factor Mash2 in the placenta, ${ }^{81}$ and are required for embryonic stem cell differentiation. ${ }^{82}$ In addition, MST1/2 play a role in differentiation of hematopoietc and endothelial progenitor cells in Xenopus, ${ }^{83}$ and MST1 was identified as a crucial caspase-3 effector in myoblast differentiation. ${ }^{84}$

For epithelial differentiation, proliferating cells of the basal cell layer withdraw from the cell cycle, progressively differentiate toward the surface of the epithelium, flatten, and lose their nucleus, before they are finally shed from the surface. This commitment and terminal differentiation also involves induction of the apoptotic machinery for controlled caspase cleavage, enucleation, and internucleosomal DNA cleavage as demonstrated in human keratinocyte differentiation. ${ }^{43-45}$ Re-localization of A-Raf in our model systems led to activation of MST2 and subsequent activation of caspase 3, cleavage of PARP, and transcriptional activation of PUMA, suggesting a direct involvement of A-Raf in epithelial differentiation.

In summary, our data and previous reports suggest that A-Raf is a crucial signaling hub controlling cellular processes such as proliferation, apoptosis, and glucose metabolism. In addition, our data suggest a potential link toward energy homeostasis control via KSR2 and AMPK, which warrants further validation. The fine-tuning of such diverse signaling events is controlled by adjusting A-Raf expression levels in normal cells and disease, alternative splice form selection, phosphorylation, and interaction with specific proteins. Here, we describe for the first time how ARAF spatial regulation through interaction with the scaffold protein KSR2 regulates MST2-mediated apoptosis and differentiation.

\section{Materials and Methods}

Immunohistochemistry. Healthy tissue and carcinoma specimen were obtained during routine biopsy or surgery after informed consent, snap frozen, cryopreserved, and processed to generate serial sections $(4 \mu \mathrm{m})$. Polyclonal goat anti-human A-Raf antibody (Santa Cruz Biotechnology, Dallas, TX, USA) was used for immunohistologic staining and antigen-antibody complexes were visualized using the avidin-biotin-peroxidase method ${ }^{85}$ Counterstaining was achieved with hematoxylin (blue).

Cell lines. HEK293 (human embryonic kidney 293 cells), NIH3T3 (mouse fibroblast cells), and MCF7 (human breast cancer cells) cells were cultured in standard DMEM containing 10\% fetal calf serum (FCS).

DNA constructs, siRNAs, and transfections. For membrane-targeted A-Raf (Flag-A-Raf-CAAX), human full-legth A-Raf was fused N-terminal with a flagtag and C-terminal with a CAAX motif (20 C-terminal amino acids of KRas $4 \mathrm{~b})^{48,49}$ and inserted into Nhel/BamHI sites of pcDNA3.1(+)-hyg (Invitrogen, Carlsbad, CA, USA)

For the rapalogue-induced recruitment of $A$-Raf to the plasma membrane, we used plasmids containing the tandem FK506-binding protein domain (2xFKBP) and the mutant FRB domain (FRB) of the ARGENT Regulated Heterodimerization Kit 
provided by ARIAD (now: iDimerize Inducible Heterodimer System; Clontech, Mountain View, CA, USA) ${ }^{55,56}$ To generate the A-Raf recruitment fusion construct (FRB-A-Raf-flag), human full-length A-Raf was amplified and subcloned into Spel/BamHI sites of pC4- $R_{H} E$ of the ARGENT Regulated Heterodimerization Kit (now: pHet-1, Clontech). As a plasma membrane target construct, we used the plasmid pC4M-F2E of the original ARGENT Regulated Heterodimerization Kit (now: pHet-Mem1, Clontech) coding for an N-terminal myristoylated tandem FK506-binding protein domain (Myr.-2xFKBP-HA).

For Flag-A-Raf ${ }_{W T}$, amplified human full-length A-Raf was fused N-terminal with a flag-tag and inserted into Nhel/BamHI sites of pcDNA3.1(+)-hyg (Invitrogen). Sitedirected mutagenesis was used to produce a kinase-dead version of A-Raf (K336M; Flag-A-Raf $\mathrm{f}_{\mathrm{KD}}$ ).

For EGFP-A-Raf, A-Raf was fused C-terminal to EGFP into Xhol/Hindlll of pEGFP-C3 (Clontech). For V5-A-Raf, A-Raf from pDONR223-ARAF (Addgene Plasmid 23725) ${ }^{86}$ was fused N-terminal with a V5-tag of pcDNA6.2/V5-DEST using Gatway technology.

For transient knockdown of A-Raf expression, we used Silencer Validated siRNA 151 (Ambion, Austin, Texas, USA) as described previously. ${ }^{21}$ For knockdown of KSR2 expression, ON-TARGETplus SMARTpool Human KSR2 (Dharmacon, Lafayette, CO, USA) was used.

Transient transfections were conducted with Lipofectamine 2000 reagent (Invitrogen) according to the manufacturer's instructions.

Immunblot analysis. Protein lysates or immunoprecipitates were resolved by SDS-PAGE (10-15\%) and blotted on polyvinylidene difluoride membrane (Millipore, Darmstadt, Germany). Protein visualization was performed using the following antibodies in combination with horseradish peroxidase-conjugated secondary antibodies and the enhanced chemiluminescence system (GE Healthcare, Little Chalfont, UK): polyclonal goat anti-human A-Raf antibody sc-30703 (Santa Cruz Biotechnology), monoclonal mouse anti-human A-Raf antibody (12C9, sc-100420; Santa Cruz Biotechnology), polyclonal rabbit anti-human MST2 antibody (Stratagene, San Diego, CA, USA), monoclonal rabbit anti-human MST2 (N terminus) antibody (Epitomics, Burlingame, CA, USA), monoclonal mouse anti-flag antibody M2 (Sigma-Aldrich, St Louis, MO, USA), monoclonal mouse anti-human tubulin antibody (Santa Cruz Biotechnology), monoclonal mouse anti-human alpha 1 sodium potassium ATPase (ATP1A1) antibody (plasma membrane marker; Abcam, Cambridge, UK), polyclonal rabbit anti-human MEK1/2 antibody (12-B, sc-436; Santa Cruz Biotechnology), monoclonal rabbit anti-human phosphorylated Mst1 (pT183)/Mst2 (pT180; Epitomics), monoclonal mouse antiHA tag antibody 3F10 (Roche Diagnostics, Risch-Rotkreuz, Switzerland), polyclonal rabbit anti-human Puma antibody (Sigma-Aldrich), polyclonal rabbit anti-human caspase-3 antibody (Santa Cruz Biotechnology), monoclonal rabbit anti-human caspase-3 antibody (8G10; Santa Cruz Biotechnology), monoclonal mouse antihuman PARP antibody (Becton Dickinson, Franklin Lakes, NJ, USA), polyclonal rabbit anti-human hnRNP H antibody, polyclonal rabbit anti-human MAPK (ERK1 and ERK2) antibody (Sigma-Aldrich), monoclonal mouse anti-human MAPKactivated (diphosphorylated ERK1 and ERK2) antibody (Sigma-Aldrich), monoclonal rabbit anti-GFP antibody (D5.1; Cell Signaling Technology, Danvers, MA, USA), monoclonal rabbit anti-human KSR1 antibody (Epitomics), mouse monoclonal antihuman KSR2 antibody (K75, sc-100421; Santa Cruz Biotechnology), polyclonal rabbit anti-human AKT antibody (Cell Signaling Technology), polyclonal rabbit antihuman activated Akt (phosphorylated at Ser473) antibody (Cell Signaling Technology), and monoclonal mouse anti-human caspase 8 (1C12; Cell Signaling Technology).

Immunoprecipitation. Immunoprecipitations were conducted as described previously ${ }^{21}$ with the following immobilized antibodies: monoclonal mouse anti-HA tag antibody 3F10 (Roche Diagnostics), monoclonal mouse anti-flag antibody M2 (Sigma-Aldrich), polyclonal goat anti-human MST2 antibody sc-6211 (Santa Cruz Biotechnology), polyclonal goat anti-human A-Raf antibody sc-30703 (Santa Cruz Biotechnology), and monoclonal mouse anti-V5-tag antibody (Invitrogen).

Apoptosis assays. Apoptosis levels were determined as described previously ${ }^{16}$ by measuring subgenomic DNA.

Subcellular fractionation. Subcellular fractionation of cytoplasmatic and plasma membrane-associated proteins was conducted with Subcellular Protein Fractionation Kit for Cultured Cells (Thermo Scientific, Waltham, MA, USA) according to the manufacturer's instructions.
Cell differentiation assay. For differentiation of MCF7 breast carcinoma cells, we used a modified protocol of a published method. ${ }^{62}$ MCF7 cells were seeded in standard 24-well plates $\left(0.4 \times 10^{6}\right.$ per well) and serum-starved (1\% FCS) $24 \mathrm{~h}$ prior to stimulation with either $10 \mathrm{nM}$ EGF (\#11376454001, Roche Diagnostics) or $2 \mathrm{nM}$ recombinant human NRG1- $\beta 1 /$ heregulin- $\beta 1$ EGF domain (heregulin; \#396-HB-050/CF, R\&D, Minneapolis, MN, USA). Following stimulation, media were changed after 2-3 days, and cells were grown for 5-6 days, before fixation with $10 \%$ paraformaldehyde in phosphate-buffered saline (PBS) for at least $1 \mathrm{~h}$. Cells were washed once with water, once with $60 \%$ isopropanol, and stained with Oil Red $\mathrm{O}$ (Sigma-Aldrich) solution for $1 \mathrm{~h}$ followed by three washes with water. Oil Red $\mathrm{O}$ (Sigma-Aldrich) stock solution was prepared by dissolving the dye in isopropanol $(0.35 \% \mathrm{w} / \mathrm{v})$, and filtered through $0.22 \mu \mathrm{m}$ filter and kept at room temperature. For cell staining, Oil Red (Sigma-Aldrich) stock solution was mixed with water in $6: 4$ ratio, and filtered through $0.22 \mu \mathrm{m}$ filter $1 \mathrm{~h}$ after precipitates were formed. Lipid accumulation in MCF7 cells was quantified by extraction of the Oil Red (Sigma-Aldrich) dye with 100\% isopropanol and measuring light absorbance of extracted dye at $500 \mathrm{~nm}$ by a standard plate reader.

Focus formation assays. Focus assays were conducted as described previously. ${ }^{21}$ NIH3T3 cells were transfected with Lipofectamine (Invitrogen) and allowed to grow to confluence. The plates were incubated for 21 days, fixed, stained with Giemsa, and the foci were counted.

Immunofluorescence and confocal microscopy. HeLa cells were plated on coverslips and co-transfected the next day with FRB-A-Raf-flag and Myr.2xFKBP-HA. Twenty-four hours post transfection, cells were treated with $500 \mathrm{nM}$ AP21967 for $1 \mathrm{~h}$ and fixed with $4 \%$ paraformaldehyde for $10 \mathrm{~min}$ at room temperature. After fixation, cells were permeabilized with $0.1 \%$ Triton X-100 (Sigma Aldrich) in PBS/1\% BSA for 2 min. Nonspecific binding was blocked by incubation with $\mathrm{PBS} / 1 \% \mathrm{BSA}$ for $30 \mathrm{~min}$ at room temperature. Incubation with flag antibody (M2, 1:200; Sigma-Aldrich) was done at room temperature for $1 \mathrm{~h}$ followed by extensive washes in PBS. Coverslips were incubated with Alexa Fluor 488conjugated secondary antibody (Molecular Probes, Eugene, OR, USA) for $30 \mathrm{~min}$ followed by several washes in PBS. The coverslips were mounted on glass slides using Vectashield containing DAPI (VECTOR LABORATORIES, Burlingame, CA, USA). Cells were imaged on a Zeiss confocal laser-scanning microscope (LSM 510 META, Zeiss, Jena, Germany). Images were acquired following excitation with 364 and 488 lasers followed by $385-470$ and $505-530 \mathrm{~nm}$ BP (band pass) filters for DAPI and Alexa Fluor 488 , respectively, with a Plan-Neofluar $\times 40 / 0.5$ or $\times 63 \mathrm{NA}$ objective.

MCF7 cells stably expressing either EGFP or A-Raf-EGFP were imaged on a Zeiss confocal laser-scanning microscope (LSM 510 META). Images were acquired following excitation with the 488 laser followed by $505-530 \mathrm{~nm}$ BP filters for EGFP, respectively, with a Plan-Neofluar $\times 40 / 0.5$ or $\times 63$ NA objective.

Statistical analysis. Significance levels were determined by two-tailed Student's t-test analyses.

\section{Conflict of Interest}

The authors declare no conflict of interest.

Acknowledgements. This work was supported by the Science Foundation Ireland under Grant No. 06/CE/B1129.

\section{Author contributions}

JR and WK conceived and designed the study and wrote the manuscript with input from all the authors. JR, DVD, BM and BMc performed the experiments. $O G$ contributed to the experimental design. NV and $A B$ provided support to the experiment.

1. Yoon S, Seger R. The extracellular signal-regulated kinase: multiple substrates regulate diverse cellular functions. Growth Factors 2006; 24: 21-44.

2. Matallanas D, Birtwistle M, Romano D, Zebisch A, Rauch J, von Kriegsheim A et al. Raf family kinases: old dogs have learned new tricks. Genes Cancer 2011; 2: 232-260.

3. Zhang XF, Settleman J, Kyriakis JM, Takeuchi-Suzuki E, Elledge SJ, Marshall MS et al. Normal and oncogenic p21ras proteins bind to the amino-terminal regulatory domain of c-Raf-1. Nature 1993; 364: 308-313. 
4. Moodie SA, Willumsen BM, Weber MJ, Wolfman A. Complexes of Ras.GTP with Raf-1 and mitogen-activated protein kinase kinase. Science 1993; 260: 1658-1661.

5. Marais R, Light Y, Paterson HF, Mason CS, Marshall CJ. Differential regulation of Raf-1, A-Raf, and B-Raf by oncogenic ras and tyrosine kinases. J Biol Chem 1997; 272: 4378-4383.

6. Han M, Golden A, Han Y, Sternberg PW. C. elegans lin- 45 raf gene participates in let- 60 rasstimulated vulval differentiation. Nature 1993; 363: 133-140.

7. McCubrey JA, Steelman LS, Hoyle PE, Blalock WL, Weinstein-Oppenheimer C, Franklin RA et al. Differential abilities of activated Raf oncoproteins to abrogate cytokine dependency, prevent apoptosis and induce autocrine growth factor synthesis in human hematopoietic cells. Leukemia 1998; 12: 1903-1929.

8. Pritchard CA, Samuels ML, Bosch E, McMahon M. Conditionally oncogenic forms of the A-Raf and B-Raf protein kinases display different biological and biochemical properties in NIH 3T3 cells. Mol Cell Biol 1995; 15: 6430-6442.

9. Baljuls A, Mueller T, Drexler HC, Hekman M, Rapp UR. Unique N-region determines low basal activity and limited inducibility of A-RAF kinase: the role of N-region in the evolutionary divergence of RAF kinase function in vertebrates. J Biol Chem 2007; 282: 26575-26590.

10. Imielinski M, Greulich H, Kaplan B, Araujo L, Amann J, Horn L et al. Oncogenic and sorafenib-sensitive ARAF mutations in lung adenocarcinoma. J Clin Invest 2014; 124: $1582-1586$.

11. Nelson DS, Quispel W, Badalian-Very G, van Halteren AGS, van den Bos C, JVMG Bovee et al. Somatic activating ARAF mutations in Langerhans cell histiocytosis. Blood 2014; 123: 3152-3155.

12. Shannon K, Hermiston M. A(nother) RAF mutation in LCH. Blood 2014; 123: 3063-3065.

13. Beazely MA, Alan JK, Watts VJ. Protein kinase $C$ and epidermal growth factor stimulation of Raf1 potentiates adenylyl cyclase type 6 activation in intact cells. Mol Pharmacol 2005; 67: 250-259.

14. Matallanas D, Romano D, Yee K, MeissI K, Kucerova L, Piazzolla D et al. RASSF1A elicits apoptosis through an MST2 pathway directing proapoptotic transcription by the p73 tumor suppressor protein. Mol Cell 2007; 27: 962-975.

15. O'Neill E, Rushworth L, Baccarini M, Kolch W. Role of the kinase MST2 in suppression of apoptosis by the proto-oncogene product Raf-1. Science 2004; 306: 2267-2270.

16. Rauch J, O'Neill E, Mack B, Matthias C, Munz M, Kolch W et al. Heterogeneous nuclear ribonucleoprotein $\mathrm{H}$ blocks MST2-mediated apoptosis in cancer cells by regulating a-raf transcription. Cancer Res 2010; 70: 1679-1688.

17. Romano D, Nguyen LK, Matallanas D, Halasz M, Doherty C, Kholodenko BN et al. Protein interaction switches coordinate Raf-1 and MST2/Hippo signalling. Nat Cell Biol 2014; 16: 673-684.

18. Yu J, Zhang L. PUMA, a potent killer with or without p53. Oncogene 2008; 27(Suppl 1): S71-S83.

19. Hagemann C, Gloger J, Anacker J, Said HM, Gerngras S, Kuhnel S et al. RAF expression in human astrocytic tumors. Int J Mol Med 2009; 23: 17-31.

20. Kisanuki H, Choi YL, Wada T, Moriuchi R, Fujiwara S, Kaneda R et al. Retroviral expression screening of oncogenes in pancreatic ductal carcinoma. Eur J Cancer 2005; 41: 2170-2175.

21. Matallanas D, Birtwistle M, Romano D, Zebisch A, Rauch J, von Kriegsheim A et al. Raf family kinases: old dogs have learned new tricks. Genes Cancer 2011; 2: 232-260.

22. Yuryev A, Ono M, Goff SA, Macaluso F, Wennogle LP. Isoform-specific localization of A-RAF in mitochondria. Mol Cell Biol 2000; 20: 4870-4878.

23. Zmuidzinas A, Gould GW, Yager JD. Expression of c-raf-1 and A-raf-1 during differentiation of 3T3-L1 preadipocyte fibroblasts into adipocytes. Biochem Biophys Res Commun 1989; 162: $1180-1187$

24. Yokoyama T, Takano K, Yoshida A, Katada F, Sun P, Takenawa T et al. DA-Raf1, a competent intrinsic dominant-negative antagonist of the Ras-ERK pathway, is required for myogenic differentiation. J Cell Biol 2007; 177: 781-793.

25. Kolch W. Coordinating ERK/MAPK signalling through scaffolds and inhibitors. Nat Rev Mol Cell Biol 2005; 6: 827-837.

26. Casar B, Arozarena I, Sanz-Moreno V, Pinto A, Agudo-lbanez L, Marais R et al. Ras subcellular localization defines extracellular signal-regulated kinase 1 and 2 substrate specificity through distinct utilization of scaffold proteins. Mol Cell Biol 2009; 29: 1338-1353.

27. Casar B, Pinto A, Crespo P. Essential role of ERK dimers in the activation of cytoplasmic but not nuclear substrates by ERK-scaffold complexes. Mol Cell 2008; 31: 708-721.

28. Therrien M, Chang HC, Solomon NM, Karim FD, Wassarman DA, Rubin GM. KSR, a nove protein kinase required for RAS signal transduction. Cell 1995; 83: 879-888.

29. Kornfeld K, Hom DB, Horvitz HR. The ksr-1 gene encodes a novel protein kinase involved in Ras-mediated signaling in C. elegans. Cell 1995; 83: 903-913.

30. Sundaram M, Han M. The C. elegans ksr-1 gene encodes a novel Raf-related kinase involved in Ras-mediated signal transduction. Cell 1995; 83: 889-901.

31. Nguyen A, Burack WR, Stock JL, Kortum R, Chaika OV, Afkarian M et al. Kinase suppressor of Ras (KSR) is a scaffold which facilitates mitogen-activated protein kinase activation in vivo. Mol Cell Biol 2002; 22: 3035-3045.

32. Therrien M, Michaud NR, Rubin GM, Morrison DK. KSR modulates signal propagation within the MAPK cascade. Genes Dev 1996; 10: 2684-2695.

33. Dougherty MK, Ritt DA, Zhou M, Specht SI, Monson DM, Veenstra TD et al. KSR2 is a calcineurin substrate that promotes ERK cascade activation in response to calcium signals. Mol Cell 2009; 34: 652-662.

34. Ohmachi M, Rocheleau CE, Church D, Lambie E, Schedl T, Sundaram MV. C. elegans ksr-1 and ksr-2 have both unique and redundant functions and are required for MPK-1 ERK phosphorylation. Curr Biol 2002; 12: 427-433.
35. Kortum RL, Johnson HJ, Costanzo DL, Volle DJ, Razidlo GL, Fusello AM et al. The molecular scaffold kinase suppressor of Ras 1 is a modifier of RasV12-induced and replicative senescence. Mol Cell Biol 2006; 26: 2202-2214.

36. Kortum RL, Lewis RE. The molecular scaffold KSR1 regulates the proliferative and oncogenic potential of cells. Mol Cell Biol 2004; 24: 4407-4416.

37. Lozano J, Xing R, Cai Z, Jensen HL, Trempus C, Mark W et al. Deficiency of kinase suppressor of Ras1 prevents oncogenic ras signaling in mice. Cancer Res 2003; 63: $4232-4238$.

38. Liu L, Channavajhala PL, Rao VR, Moutsatsos I, Wu L, Zhang Y et al. Proteomic characterization of the dynamic KSR-2 interactome, a signaling scaffold complex in MAPK pathway. Biochim Biophys Acta 2009; 1794: 1485-1495.

39. Costanzo-Garvey D, Pfluger P, Dougherty M, Stock J, Boehm M, Chaika $O$ et al. KSR2 is an essential regulator of AMP kinase, energy expenditure, and insulin sensitivity. Cell Metab 2009; 10: 366-378.

40. Fernandez MR, Henry MD, Lewis RE. Kinase suppressor of Ras-2 (KSR2) regulates tumor cell transformation via AMPK. Mol Cell Biol 2012; 32: 3718-3731.

41. Pearce LR, Atanassova N, Banton MC, Bottomley B, van der Klaauw AA, Revelli J-P et al. KSR2 mutations are associated with obesity, insulin resistance, and impaired cellular fuel oxidation. Cell 2013; 155: 765-777.

42. Wang $\mathrm{X}$, Wang T-T, White JH, Studzinski GP. Expression of human kinase suppressor of Ras 2 (hKSR-2) gene in HL60 leukemia cells is directly upregulated by 1,25 dihydroxyvitamin D(3) and is required for optimal cell differentiation. Exp Cell Res 2007; 313: 3034-3045.

43. McCall CA, Cohen JJ. Programmed cell death in terminally differentiating keratinocytes: role of endogenous endonuclease. J Invest Dermatol 1991; 97: 111-114.

44. Weil M, Raff MC, Braga VM. Caspase activation in the terminal differentiation of human epidermal keratinocytes. Curr Biol 1999; 9: 361-364.

45. Lu QL, Abel P, Foster CS, Lalani EN. bcl-2: role in epithelial differentiation and oncogenesis. Hum Pathol 1996; 27: 102-110.

46. Shilo A, Ben Hur V, Denichenko P, Stein I, Pikarsky E, Rauch J et al. Splicing factor hnRNP A2 activates the Ras-MAPK-ERK pathway by controlling A-Raf splicing in hepatocellular carcinoma development. RNA 2014; 20: 505-515.

47. Denecker G, Ovaere P, Vandenabeele P, Declercq W. Caspase-14 reveals its secrets. J Cell Biol 2008; 180: 451-458.

48. Stokoe D, Macdonald SG, Cadwallader K, Symons M, Hancock JF. Activation of Raf as a result of recruitment to the plasma membrane. Science 1994; 264: 1463-1467.

49. Leevers SJ, Paterson HF, Marshall CJ. Requirement for Ras in Raf activation is overcome by targeting Raf to the plasma membrane. Nature 1994; 369: 411-414.

50. Lee KK, Ohyama T, Yajima N, Tsubuki S, Yonehara S. MST, a physiological caspase substrate, highly sensitizes apoptosis both upstream and downstream of caspase activation. J Biol Chem 2001; 276: 19276-19285.

51. Terai K, Matsuda M. Ras binding opens $c$-Raf to expose the docking site for mitogenactivated protein kinase kinase. EMBO Rep 2005; 6: 251-255.

52. Raabe T, Rapp UR. Ras signaling: PP2A puts Ksr and Raf in the right place. Curr Biol 2003; 13: R635-R637.

53. Goetz CA, O'Neil JJ, Farrar MA. Membrane localization, oligomerization, and phosphorylation are required for optimal raf activation. J Biol Chem 2003; 278: 51184-51189.

54. Rommel C, Radziwill G, Lovric J, Noeldeke J, Heinicke T, Jones D et al. Activated Ras displaces 14-3-3 protein from the amino terminus of c-Raf-1. Oncogene 1996; 12: 609-619.

55. Belshaw PJ, Ho SN, Crabtree GR, Schreiber SL. Controlling protein association and subcellular localization with a synthetic ligand that induces heterodimerization of proteins. Proc Natl Acad Sci USA 1996; 93: 4604-4607.

56. Klemm JD, Schreiber SL, Crabtree GR. Dimerization as a regulatory mechanism in signal transduction. Annu Rev Immunol 1998; 16: 569-592.

57. Bacus SS, Huberman E, Chin D, Kiguchi K, Simpson S, Lippman M et al. A ligand for the erbB-2 oncogene product (gp30) induces differentiation of human breast cancer cells. Cell Growth Differ 1992; 3: 401-411.

58. Giani C, Casalini P, Pupa SM, De Vecchi R, Ardini E, Colnaghi Ml et al. Increased expression of c-erbB-2 in hormone-dependent breast cancer cells inhibits cell growth and induces differentiation. Oncogene 1998; 17: 425-432.

59. Guilbaud NF, Gas N, Dupont MA, Valette A. Effects of differentiation-inducing agents on maturation of human MCF-7 breast cancer cells. J Cell Physiol 1990; 145: 162-172.

60. Kim KY, Kim SS, Cheon HG. Differential anti-proliferative actions of peroxisome proliferatoractivated receptor-gamma agonists in MCF-7 breast cancer cells. Biochem Pharmacol 2006; 72: $530-540$.

61. Martirosyan AR, Rahim-Bata R, Freeman AB, Clarke CD, Howard RL, Strobl JS. Differentiation-inducing quinolines as experimental breast cancer agents in the MCF-7 human breast cancer cell model. Biochem Pharmacol 2004; 68: 1729-1738.

62. Nagashima T, Shimodaira H, Ide K, Nakakuki T, Tani Y, Takahashi K et al. Quantitative transcriptional control of ErbB receptor signaling undergoes graded to biphasic response for cell differentiation. J Biol Chem 2007; 282: 4045-4056.

63. Farrell J, Kelly C, Rauch J, Kida K, Garcia-Muñoz A, Monsefi N et al. HGF induces epithelialto-mesenchymal transition by modulating the mammalian Hippo/MST2 and ISG15 pathways. J Proteome Res 2014; 13: 2874-2886.

64. Rauch J, Kolch W. A-Raf / v-raf murine sarcoma 3611 viral oncogene homolog. UCSDNature Molecule Pages, 2010 (doi:10.1038/mp.a000307.01). Available from http://www. signaling-gateway.org/molecule/query?afcsid $=\mathrm{A} 000307$. 
65. Ory S, Zhou M, Conrads TP, Veenstra TD, Morrison DK. Protein phosphatase 2A positively regulates Ras signaling by dephosphorylating KSR1 and Raf-1 on critical 14-3-3 binding sites. Curr Biol 2003; 13: 1356-1364.

66. Abraham D, Podar K, Pacher M, Kubicek M, Welzel N, Hemmings BA et al. Raf-1-associated protein phosphatase $2 \mathrm{~A}$ as a positive regulator of kinase activation. J Biol Chem 2000; 275: 22300-22304.

67. Jaumot M, Hancock JF. Protein phosphatases 1 and 2 A promote Raf-1 activation by regulating 14-3-3 interactions. Oncogene 2001; 20: 3949-3958.

68. Weber CK, Slupsky JR, Herrmann C, Schuler M, Rapp UR, Block C. Mitogenic signaling of Ras is regulated by differential interaction with Raf isozymes. Oncogene 2000; 19: 169-176.

69. Baljuls A, Schmitz W, Mueller T, Zahedi R, Sickmann A, Hekman M et al. Positive regulation of A-RAF by phosphorylation of isoform-specific hinge segment and identification of novel phosphorylation sites. J Biol Chem 2008; 283: 27239-27254.

70. Rauch J, Ahlemann M, Schaffrik M, Mack B, Ertongur S, Andratschke M et al. Allogenic antibody-mediated identification of head and neck cancer antigens. Biochem Biophys Res Commun 2004; 323: 156-162.

71. Mazurek S, Drexler HC, Troppmair J, Eigenbrodt E, Rapp UR. Regulation of pyruvate kinase type M2 by A-Raf: a possible glycolytic stop or go mechanism. Anticancer Res 2007; 27: 3963-3971.

72. Christofk HR, Vander Heiden MG, Harris MH, Ramanathan A, Gerszten RE, Wei R et al. The M2 splice isoform of pyruvate kinase is important for cancer metabolism and tumour growth. Nature 2008; 452: 230-233.

73. Gomez M, Gomez V, Hergovich A. The Hippo pathway in disease and therapy: cancer and beyond. Clin Transl Med 2014; 3: 22.

74. Yu FX, Guan KL. The Hippo pathway: regulators and regulations. Genes Dev 2013; 27: 355-371.

75. Harvey KF, Zhang X, Thomas DM. The Hippo pathway and human cancer. Nat Rev Cancer 2013; 13: 246-257.
76. Wang W, Huang J, Chen J. Angiomotin-like proteins associate with and negatively regulate YAP1. J Biol Chem 2011; 286: 4364-4370.

77. Wang Y, Li Z, Xu P, Huang L, Tong J, Huang H et al. Angiomotin-like2 gene (amotl2) is required for migration and proliferation of endothelial cells during angiogenesis. $\mathrm{J}$ Biol Chem 2011; 286: 41095-41104.

78. Zhao $B$, Li L, Lu Q, Wang LH, Liu CY, Lei $Q$ et al. Angiomotin is a novel Hippo pathway component that inhibits YAP oncoprotein. Genes Dev 2011; 25: 51-63.

79. Bernascone I, Martin-Belmonte F. Crossroads of Wnt and Hippo in epithelial tissues. Trends Cell Biol 2013; 23: 380-389.

80. Gao T, Zhou D, Yang C, Singh T, Penzo-Mendez A, Maddipati R et al. Hippo signaling regulates differentiation and maintenance in the exocrine pancreas. Gastroenterology 2013; 144: 1543-1553, 1553.e1.

81. Du X, Dong Y, Shi H, Li J, Kong S, Shi D et al. Mst1 and mst2 are essential regulators of trophoblast differentiation and placenta morphogenesis. PLoS One 2014; 9: e90701.

82. Li P, Chen Y, Mak KK, Wong CK, Wang CC, Yuan P. Functional role of Mst1/Mst2 in embryonic stem cell differentiation. PLoS One 2013; 8: e79867.

83. Nejigane S, Takahashi S, Haramoto Y, Michiue T, Asashima M. Hippo signaling components, Mst1 and Mst2, act as a switch between self-renewal and differentiation in Xenopus hematopoietic and endothelial progenitors. Int J Dev Biol 2013; 57: 407-414.

84. Graves JD, Gotoh Y, Draves KE, Ambrose D, Han DK, Wright M et al. Caspase-mediated activation and induction of apoptosis by the mammalian Ste20-like kinase Mst1. EMBO J 1998; 17: 2224-2234

85. Hsu SM, Raine L, Fanger $\mathrm{H}$. The use of antiavidin antibody and avidin-biotin-peroxidase complex in immunoperoxidase technics. Am J Clin Pathol 1981; 75: 816-821.

86. Johannessen CM, Boehm JS, Kim SY, Thomas SR, Wardwell L, Johnson LA et al. COT drives resistance to RAF inhibition through MAP kinase pathway reactivation. Nature 2010; 468: 968-972.

Supplementary Information accompanies this paper on Cell Death and Differentiation website (http://www.nature.com/cdd) 